\title{
Life satisfaction analysis of occupational balance group: based on Korean time use survey data (KOSTAT) of older adults
}

Yu-Jin Cha ( $D$ occujin@naver.com )

\section{Research article}

Keywords: Life satisfaction, Lifestyle redesign, Occupational balance, Older adults, Time-use management., Time use survey,

Posted Date: October 1st, 2019

DOI: https://doi.org/10.21203/rs.2.15398/v1

License: (c) (i) This work is licensed under a Creative Commons Attribution 4.0 International License. Read Full License 


\section{Abstract}

Background: The purpose of this study was to identify whether there is a difference in time use between a group of subjects with occupational balance, the occupational balance group (OB group) and a group of subjects lacking occupational balance, the occupational imbalance group (OI group), and what factors influence the life satisfaction of the OB group. This study used raw data from the 2014 Time Use Survey of the Korea National Statistical Office (KOSTAT). Methods: This study sorted detailed activities of the 9.228 subjects who were over 65 years of age. We conducted an independent sample t-test to confirm the time difference by areas between the OB group and the OI groups. In order to confirm the effect of variables on life satisfaction, we performed regression analysis by applying an ordered probit model (OPM). Results: The analysis of time use corresponding to eight activity areas showed the greatest time use for the instrumental activities of daily living (IADL), followed by rest and sleep, leisure, and activities of daily living (ADL). The largest effect size (ES) was social participation, followed by leisure, IADL, and work. As a result of analyzing the factors affecting the life satisfaction of the OB group, we found that lower age, females, a higher level of education, a lower need for care, higher income, and agricultural residence tended to correspond to higher life satisfaction. Conclusions : This study may provide a basis for the development of the time-use management and lifestyle redesign programs to assist older adults in pursuing disease prevention and health maintenance roles by themselves.

\section{Background}

Most notable welfare countries and governments strive to guarantee happiness by drawing up and implementing various policies to support the goal of 'improving the life satisfaction, quality of life (QoL) or well-being' with the aim of raising the level of happiness of the people. Examining at the policy goals of Korean welfare programs for older adults, the importance of the concept of life satisfaction is clearly revealed. You can see that in most cases, the policy goal of this project is focused on "the QoL of older adults" and that "life satisfaction" serves as a core element in attaining "QoL". Accordingly, every policy in Korea regarding the elderly emphasizes life satisfaction as an important social task, and seeks to raise it for the elderly [1]. The type of activity and time use can never be separated because they are important criteria in determining lifestyle, improvement of life, and even life satisfaction [2]. This does not refer merely to life extension but to exercising control over one's life based on healthy life in old age. Successful aging is possible when a person lives a proper life in balance with occupations [3].

The Republic of Korea (ROK) has become an aging society later than Europe and Japan. But as 2050 approaches, the proportion of the ROK population aged 65 and over will surge, and it is predicted that Korea will become a world-class super-aged society. The society of the ROK, which has just become an aging society, urgently needs to solve various problems faced by older adults who have psychological anxiety due to loss of body function and income reduction [4]. As the size of the older adults group increases and its influence grows with the aging of the society, the analysis of the use pattern of living time has a great social significance [5]. Management should be planned regarding the balance of selfcare, work, leisure, and relaxation to enhance life satisfaction and health [6]. 
According to the Survey of Household Finance and Welfare (2017) by the Korea National Statistical Office (KOSTAT), the average retirement age of householders in Korea is 62.1 years old, which means they have to live for more than 20 years without regular income after retirement [7]. In 2016, only 7.1\% of the Korean population were pension recipients, but this reflects a steady increase from $3.0 \%$ in 2013 and $4.38 \%$ in 2014. This indicates retirees have been recognizing the importance of regular cash flow by gradation [8]. Unlike other countries, in Korea, National Health Service (NHS) spending occupies a strictly high proportion of the public medical security system.

The medical expenditure of older adults for health insurance rose very rapidly from 2010 to 2016, in proportion to the growing population of the aged. In 2016, there were 6.45 million people aged 65 or over that received national health care benefits, accounting for $12.7 \%$ of the whole population. The medical expenditure was 25 trillion 18.7 billion KRW, accounting for $58.7 \%$ of their entire expenditure. The monthly average medical expenditure per capita among those aged 65 or over was 3.1 times greater than the monthly average medical expenditure of the whole population [9]. Therefore, it is possible to provide evidence supporting the intervention of time use and for developing programs by ascertaining the patterns of time use by older Korean adults in their living after retirement and determining the correlation between this, health and life satisfaction.

Time use is employed to evaluate occupational balance (OB). OB refers to a status wherein labor, rest and the amounts of time for labor and rest are distributed at an appropriate ratio and occupational imbalance (OI) occurs when the excessive use of time in one area worsens health or the quality of life [10,11]. OB refers to a balanced participation by individuals in their daily occupational life [12]. In the study by Matuska and Christiansen, $\mathrm{OB}$ refers to a condition in which a person can live a healthy and meaningful life in a given day-to-day occupational life [13]. Maintaining a good balance of occupation means using living time in the activity areas that one needs in an appropriate distribution. OB perceived by an individual is likely to be influenced by the amount of time spent in everyday occupation. Time-use is used to evaluate $\mathrm{OB}$ and occupational engagement [14]. If the $\mathrm{OI}$ is precipitated by a time imbalance, the level of health and life satisfaction will deteriorate. Therefore, the time use of the subjects should be grasped and should be included in any goal setting and intervention. The OI causes the imbalance of the remaining activity areas as a result of a one-sided occupational performance pattern, which can ultimately deteriorate the life satisfaction and health, lead to impairment or disease and hinder successful aging [15]. Therefore, understanding time use is necessary in assessing the OB, which shows how to choose mandatory and non-mandatory activities according to the value of an individual $[14,16]$.

Effective time use shows good time management and outstanding self-management skills. These selfmanagement skills balance a person's needs and emotions and include proper management of temporal demands [17]. The study of 24 hours of living time can allow us to grasp the everyday life of an individual and the social structure around the individual. In particular, this temporal approach is suitable for dealing with the daily living of older adults, which is difficult to grasp by other official and economic approaches [18]. 
In the research comparing time use between older Korean adults and older foreign adults, older Korean adults spent the greatest number of hours in IADL among the seven activity areas other than rest and sleep. They spent the greatest portion of the day doing IADL, including housework and taking care of grandchildren and family members. This was followed by leisure and work. They primarily spent their leisure time using media and the majority of work was unpaid family affairs or volunteer work, not paid work.

Based on the results of American Time Use Surveys (ATUS), older adults in the US spent the greatest number of hours in leisure among the seven activity areas other than rest and sleep The older adults in the US spent time engaged in diverse sports activities like playing golf, walking and swimming and leisure activities, including using media [19]. This was followed by IADL activities such as housework and gardening, and social activities to connect with family members and friends. But they spent very little time on working, playing or learning [20].

Occupation is an activity that has a unique meaning and purpose in the life of an individual and is at the center of individual identity and competence, which influences the individual in spending time and making decisions [6]. Occupation is important enough to be considered as a part of a life description, and experiencing meaningful occupation has a positive impact on health [21]. Occupation is very critical to human beings and occupation and time have an inseparable relationship with each other, since people are involved in occupations every hour [22]. Participation involves the balance of activities as well as diversity, meaning, and social factors of everyday use [23]. In order to determine the relationship between occupational engagement and health, occupational therapists have studied various concepts where $\mathrm{OB}$ is one of the important concepts. Experience of meaningful occupation has a positive impact on health and therefore, participating in a task successfully reflects the subjective value of an individual [24].

$\mathrm{OB}$ is very important to human beings and for older adults, maintaining $\mathrm{OB}$ adequately is directly connected to good health. This motivates humans to plan and manage their lives for quality. In particular, people who are not sufficiently provided with an opportunity to work suffer damaged health and eventually they have a difficulty surviving. This demonstrates that OI may cause damage to health or a disease by worsening qualitative aspects of health and life [3]. Countries, therefore, need to be more aggressive in providing environments for older adults to improve their life satisfaction by maintaining $\mathrm{OB}$ or in establishing and enforcing older adults health care policies by developing health programs considering the physical abilities of older adults or by cultivating specialists [25].

Studies on time use and life satisfaction in the ROK's occupational therapy field have mainly focused on spinal cord injury, schizophrenia, multiple sclerosis and rheumatoid arthritis patients [26]. Time use and life satisfaction programs are reported to have a positive effect on the recovery of various functions by numerous chronic and severely handicapped persons as well as normal people [16]. Kim, Lee, and Jeon reported that they applied a lifestyle re-design program to older adults with dementia to improve their productivity as well as their life satisfaction [27]. There was a systematic review of time use that 
analyzed the amount of time use through a survey of the time spent by healthy elders, analyzing the changes in time use by age and by year according to the occupation of South Koreans and so on [28].

In early studies in Korea and abroad, those on the occupational balance analyzed how time use varies in labor, self-management, and leisure [29]. In many studies, the OB has been dealt with in the sense of personally perceived balance $[14,30]$. Bejerholm and Eklund analyzed that the time use of schizophrenic patients revealed a pattern that caused problems in their performance, and suggested that time management specialists should provide these clients with mediation to support their effective time use [31].

Activity theory explains that individuals accomplish successful aging when they maintain proper social activities. That is, life satisfaction is higher as older adults find activities which can serve as substitutes for personal goals they had desired to attain in their occupation and life before reaching senility and as they are actively engrossed in such activities. This theory is made up of four pillars - social activity (the quantity of and the individual's interaction), social adequacy (the quality of an individual's social interaction as expressed in feelings of loneliness or its opposite), self-conception (the individual's image of his own worth as a person), life satisfaction (relative happiness with present circumstances in the context of one's lifetime experiences). It was supposed that the four pillars, making both direct and indirect influence, form a causal chain in the order given [32].

Conversely, disengagement theory argues that social individuals are progressively separate from or drop out of the role system of middle age, as they enter old age and that this is a universal and indispensable process for the maintenance and sustainable development of the social system. Continuity theory remedies the weaknesses of the two conflicting theories; activity theory and disengagement theory and says a good social activity in old age continuously performs a similar role, focusing on personal disposition and the role performed in middle age. This continuity theory is presented as a conceptual indicator of social activities for the aged [33].

Currently, it is necessary to provide supporting data to determine elders' health promotion and health care policy by verifying the $\mathrm{OB}$ through the living time of older adults. However, there are still few studies on the life satisfaction of older adults in the ROK after dividing the OB group and the OI group. For the OB group, all of eight activity areas are included in the scope of standard deviation, based on the mean value of life time. The OI group includes cases where even one of the areas is beyond the scope of standard deviation [27].

The purpose of this study was to identify whether there is a difference in time use by criteria (eight activity areas in total) and what factors influence the life satisfaction of those in the OB group. To this end, we confirmed the use type of living time of older adults targeting healthy elders over 65 years of age in the ROK by classifying them into the OB group and the OI group. Based on the results of this study, we may identify the relationship among occupation, old age, health, and life satisfaction, and establish a retirement planning model for future generations of older adults' as well as older adults' households. We 
expect that this study will have important implications as a basis for intervention regarding time use and as basic material for program development.

\section{Methods}

\section{Data and sample}

According to the Korea National Statistical Office (KOSTAT), the number of subjects in the 2014 Korean Time Use Survey (KTUS) was 26,988. This study sorted detailed activities of the 9.228 subjects who were over 65 years of age. The term healthy elders here refer to men or women aged 65 or more who are able to walk or drive independently, managing daily living on their own without epidemic or a serious chronic disease. This study used the raw data of 2014 KTUS of the KOSTAT, and classified the amount of time use of older adults into eight activity areas in total such as ADL, IADL, rest and sleep, education, work, play, leisure, and social participation [22] (Appendix 1).

Overview of the survey

We defined the OB group as the cases where all eight activity areas fell within the standard deviation range based on the average value of living time. We identified the OI group as the cases where any item or items deviated from the standard deviation range. At this time, we analyzed the cases under 1 standard deviation (SD) from the mean or the cases over 1 SD from the mean [27].

Analysis method and main variables

We conducted independent sample t-tests to confirm the time difference by area (eight areas in total) between the $\mathrm{OB}$ group and the OI groups. We presented graphs to visually confirm the amount of living time. In order to confirm the effect of variables on life satisfaction, we performed regression analysis by applying an ordered probit model (OPM). In the survey, life satisfaction, which is a dependent variable of the time use is measured with an ordinal-type Likert scale. The OPM is a model that depends on the error of the standard normal distribution because it does not satisfy the basic assumption of the general linear regression equation. We used a statistical program SPSS 18.0 to analyze the frequency of general characteristics of the study subjects.

\section{Results}

The amount of time uses by activity areas

For the amount of time use according to the occupational type of study subjects, we attained the following results. The greatest time use was IADL, which averaged 1513.59 minutes (56.34\%), the 
average of rest and sleep was 532.82 minutes (19.83\%), of leisure was 292.83 minutes (10.9\%), and of ADL was 185.47 minutes (6.9\%) in order. In this study, we classified the cases within 1 standard deviation as falling in the occupational balance group. IADL showed $1213.99 \sim 1813.19$ minutes, rest and sleep $422.39 \sim 643.26$ minutes, leisure time $126.06 \sim 459.59$ minutes, and ADL $126.16 \sim 244.79$ minutes. We represented the amount of living time by a graph in order to confirm it visually (Figure 1 and Table 1 ).

Comparison of time use between the $\mathrm{OB}$ group and the OI group

The time-use between the OB group $(n=2,153)$ and the OI group $(n=7,075)$ showed significant difference in $A D L, I A D L$, rest and sleep, leisure, work, play, and social participation, but no significant difference in education $(p=.001)$. Independent sample t-tests were conducted in order to confirm the difference in time by the eight activity areas according to occupational balance. A Welch-Aspin test was used instead of ttest if there was heteroskedasticity of the distribution of dependent variable as a result of the Levene-test. Compared to the OI group, the OB group used more time in $\mathrm{ADL}(\mathrm{t}=12.39, p=.001), \mathrm{IADL}(\mathrm{t}=28.21, p=$ $.001)$, rest and sleep $(\mathrm{t}=-25.65, p=.001)$, and leisure $(\mathrm{t}=27.99, p=.001)$ while it used less time in occupation ( $\mathrm{t}=-25.65, p=.001)$, play $(\mathrm{t}=-5.85, p=.001)$ and social participation $(\mathrm{t}=-80.73, p=.001)$. The effect size (ES) is known as Cohen's $d$ [34], and the ES increases as the difference between the two groups to be compared increases. Therefore, the activity areas with the largest time use difference between the two group were social participation (1.38), followed by leisure (0.66), IADL (0.59) and work (0.51) (Figure 2 and Table 2).

Factors affecting the life satisfaction of the OB group

In order to confirm the factors affecting the life satisfaction of the OB Group, we conducted regression analysis applying an ordered probit model (OPM). The life satisfaction, which is a dependent variable of KTUS, has a 5-point scale selection-type category displaying from $₫$ Very Unsatisfactory to $\otimes$ Very Satisfactory, and the order among categories was meaningful. The static effect was significant in the case of age. The static effect was significant in males more than in the females $(B=-0.12, p<.05)$, in middle school more than no educational attainment $(B=0.28, p<.01)$, high school than no educational attainment $(B=0.48, p<.001)$, college and university than no educational attainment $(B=0.65, p<.001)$, stroke than needs no help for $A D L(B=-1.19, p<.01)$, disability than needs no help for $A D L(B=-1.00, p<$ $.001)$, other reasons than no needs help for $A D L(B=-0.68, p<.001)$, less than KRW one million compared to over KRW three million $(B=-0.43, p<.001)$, KRW one million compared to less than KRW two million, less than KRW two million compared to KRW three million $(B=-0.32, p<.001)$, and lastly agricultural residence than non-agricultural residence $(B=0.29, p<.001)$. KRW is a combination of Korea's country code 'KR(Korea, Republic)' and the monetary unit 'Won' and is an abbreviation of 'Korean Won'. As a way of describing the spot exchange rate, the counter currency to the base currency is USD/KRW $=1,124$ Won. 
As a result of analysis, life satisfaction was higher in the case of middle school, high school, college or above than the cases of young age, female and no education. In the case of the reason for needing care, it turned out that the less need for care for stroke, disability, and other reasons, the higher the average annual household income (higher than KRW 3 million), and the more agricultural residence, the higher the life satisfaction (Table 3). Of the total 9,228 old people over 65 years old, those with work turned out to be 2,848 persons (30.9\%), without work 6,380 (69.1\%), full-time work $602(6.5 \%)$ and part-time work 516 (5.6\%).

In accordance with the 2014 data provided by the International Monetary Fund (IMF), Korea's GDP per capita is 14,495 (one hundred million/\$), which is 0.08 times lower than 174,163 (one hundred million/\$) of the U.S.A. and 0.30 times lower than 47,698 (one hundred million/\$) of Japan [35]. The monthly average income per household as researched by the Korea National Statistical Office (KOSTAT) in 2014 was 4,302,000 KRW. In the index of five income brackets depending on income level, the low income class belongs to the first bracket and its monthly average income was 1,460,000 KRW, the second bracket's monthly average income was $2,866,000 \mathrm{KRW}$, the third bracket's monthly average income was $3,917,000 \mathrm{KRW}$ and the fourth bracket's monthly average income was 5,136,000 KRW. The high income class belongs to the fifth bracket and its monthly average income was 8,129,000 KRW [36].

\section{Discussion}

For anyone, there are 24 hours in a day. As a quantitative size, time of a day is given to everyone equally, but people have different ways of spending a day. Also, the quality of time may be different, even though the same amount of time is given to individuals and it is affected by the limitations of their financial conditions and their environments [37]. This study classified healthy older adult subjects in the ROK into an OB group and an OI group using the data of the 2014 KTUS by the KOSTAT. We conducted this study to investigate whether there are differences in time use for occupation by category (eight in total) and the factors affecting the life satisfaction of the OB group.

As a result, the time use according to the type of occupation was the highest in IADL, followed by rest, sleep, and ADL respectively. IADL is an activity that supports daily living at home and community, requiring more complex interactions than activities primarily used in ADL. For example, it includes care, home care, shopping, religious and spiritual activities, food preparation and cleaning, driving and community mobilization. The Korean older adults are found to spend the greatest amount of time in a day doing IADL and leisure activities, which are static activities indoors. Specifically, this agrees to the result of foregoing studies that the older adults spend most of their time doing everyday household chores as IADL and some other time taking care of a grandchild or a family member as well [20].

As a result of comparing the time use, ADL, IADL, rest and sleep, leisure, work, play, and social participation showed significant differences, while time use for education showed no significant difference. The largest ES was social participation (1.38), followed by leisure (0.66), IADL (0.59), and work (0.51). Thus, the activity areas with the largest time use difference between the two groups were 
social participation, followed by leisure, IADL, and work. The OB group showed a higher amount of time use than the OI group in leisure, IADL, rest and sleep, and ADL while a lower amount of time-use than the OIG in work, play, and social participation. This aligns with foregoing studies which reported that the older adults who have enjoyed continued leisure activities show a lower tendency of depression and higher satisfaction with everyday life than those who don't participate in leisure activities, regardless of their type [38].

Compared to the OI group, the $\mathrm{OB}$ group spent more time in $\mathrm{ADL}$, IADL, rest and sleep, and leisure and less time in occupational, play, and social participation. This result contradicts the result of the study referring to social participation and proper occupation in old age, which are related to mutual exchange with other people, as essential elements for improving and maintaining the life satisfaction of older adults [39]. According to socioemotional selectivity theory (SST), the aged consciously reduce the frequency of social contact to spend more time on the emotionally compensating relationship, such as family or friends. Therefore, the aged belonging to the $\mathrm{OB}$ group are found to seek to enhance life satisfaction by reducing social networks selectively. Based on SST, this study proposes that in developing social relationship activity services for the older adults' life satisfaction, they minimize emotional risk and maximize positive emotional experience by spending more time with close friends or family members, rather than forming new relationships.

As a result of analyzing the factors affecting life satisfaction of the OB Group, we confirmed the following. Higher life satisfaction corresponded to those younger, females more than males, higher levels of education, lower need for care, higher income, and agricultural residence. This is consistent with the study result by Jeon which discovered that the younger, and more females than males, the more use of living time of the occupational balance type, and the study result which discovered that the younger, the more active, and that the more females than males, the higher the level of basic activities and instrumental activities [3].

The effects of cultural factors such as education level and residence area on time use are also reported in various forms. It is pointed out that the influence of cultural factors such as education level and environment of individual in relation to leisure is greater than that of economic factors such as income and occupation. This is because, through education, one can maintain a high level of stimulation, culture, and insight necessary for leisure activities [40]. This result is consistent with that of the studies which discovered that the higher the level of education, the higher the life satisfaction of older adults in the expectation that the persons with higher education have better financial status and higher life satisfaction than usual [41]. In other words, the higher the economic and educational level of older adults are, the more important and decisive the close relationship with self-development and socio-cultural activities is to the life satisfaction of older adults [39]. The result of this study shows that as average monthly household income becomes higher, daily life satisfaction is higher, too, despite the insignificance of economic activity status. It also implies that based on SST, we can have a broader span of social choice that can optimize older adults' psychological and emotional satisfaction. It agrees with the 
foregoing studies on successful aging in Korea in that the older adults' diverse economic and social activity of production are very important components of successful life in one's declining years [3].

We can estimate the hours of living in the type of occupational balance with the amount of the time used through analyzing the data of 2014 Time Use Survey of the KOSTAT. Many studies on occupational balance have reported that it makes an important influence on human life satisfaction and health $[10,14$, 15]. Therefore, it will be possible to increase older adults' life satisfaction and health by developing lifestyle redesign programs for them, and other methods to provide an opportunity for balance. For successful aging, one needs training that can distribute living time appropriately as well as help from a time intervention specialist to make it a habit.

This study has limitations in investigating the satisfaction and importance of time use in KTUS as well as in understanding the use of living time according to the social environment and characteristics of individuals. We expect that future surveys of living time may supplement the limitations. In addition, since sociocultural differences among the countries have some effect on the living time of older adults, future studies should analyze the factors determining the $\mathrm{OB}$ based on the theories of sociocultural differences among nations in terms of living time use. Though this study was a survey made on healthy older adults, absence of a measure of health can be a limitation. In foregoing studies reviewing the influence of health condition on life satisfaction, the satisfaction with health felt subjectively was one of the important variables that predicted life satisfaction [42]. It is considered that in future studies, there will be need to compose logic by applying variables with a measure of subjective and objective health conditions.

This study has significance in that it analyzed the living time of older adults over 65 years of age in terms of occupational type, and this analysis will help the clients with difficulty in time use as well as healthy elders perform their daily tasks in the way of occupational performance. Various methods should be suggested to maintain the $\mathrm{OB}$ for the successful aging of older adults.

\section{Conclusions}

Based on the results of this study, we identified the relationship among occupation, old age, health and life satisfaction, so that we can effectively establish old-age preparation plans for the current older adults' generation as well as future older adults' generations. We expect that the results will have important implications as a basis for use mediation and program development. This study may be generalized because it ensured objectivity by using the raw materials from the living time research by the KOSTAT, rather than personally verified and researched time data. This study may provide a basis for the development of time-use management and lifestyle redesign programs in order for older adults to practice the disease prevention and health maintenance roles by themselves.

\section{Abbreviations}


A: activities of daily living; ATUS: American Time Use Surveys; E: education; ES: effect size; I: instrumental activities of daily living; IMF: International Monetary Fund; KOSTAT: Korea National Statistical Office; KRW: Korean Won; KTUS: Korean Time Use Survey; L: leisure; NHS: National Health Service; OB: occupational balance; OI: occupational imbalance; OPM: ordered probit model; P: play; QoL: quality of life; R: rest and sleep; ROK: Republic of Korea; S: social participation; SD: standard deviation; SST: socioemotional selectivity theory; W: work

\section{Additional Files}

See Appendix 1 for reclassification of eight activity areas on detailed activities in Korean time use survey (KTUS) 2014. This study, sub-activities in raw data of 'Time Use Survey 2014' were categorized into total eight activity areas (activities of daily living, instrumental activities of daily living, rest and sleep, work, education, play, leisure, social participation). It based on eight 'activity areas' suggested by OTPF-3.

Activity of daily life (ADL) is activity with a focus on taking care of one's own body [43] including eating, personal hygiene, dressing, makeup, etc. while interactive activity of daily life (IADL) refers to supporting daily life within home and community involving interactions more complex than activity chiefly used in ADLs and including food preparation, household management, teaching children, etc. Rest and sleep are the activities related to obtaining restorative rest and sleep to support healthy and active engagement in other occupations, including sleeping, sick leave, idling, etc. Education refers to the activity needed to learn and participate in an educational environment, including class time, self-study, leisure and liberal arts, learning, etc. Work refers to occupations with or without financial reward [44], including major jobs, agriculture, forestry and fishery work for self-consumption and other volunteer work. Play refers to spontaneous or organized activity which provides enjoyment, entertainment, amusement or diversion, including group games and recreation, computer and mobile game, entertainment, etc. Leisure refers to non-obligatory activity with intrinsically motivated participation during discretionary time [45], including watching TV, Internet surfing, personal hobbies, etc. Social participation refers to participation in the subset of activities involving social situations with others [46], including face-to-face encounter, interactions via text and mail exchange, other fellowship activities, etc.

\section{Declarations}

\section{Acknowledgments}

YJC would like to thank Semyung University for funding this study and the Korean National Statistical Office for sharing data.

\section{Funding}

This paper was supported by a 2017 Semyung University Research Grant. 


\section{Availability of data and materials}

The datasets used and/or analysed during the current study are available from the corresponding author on reasonable request.

\section{Ethics approval and consent to participate}

The data used to support the findings of this study were provided by Korean National Statistical Office (KNSO) under license. I obtained an exemption from the Institutional Review Board at the Semyung University (SMU-2017-EX-03-003)."

\section{Consent for publication}

Not applicable

\section{Conflicting interests}

The author declares that he has no competing interests.

\section{Author details}

Department of Occupational Therapy, Semyung University, Jecheon, Republic of Korea.

\section{References}

1. Han HS. A study on objective indicator and subjective satisfaction on the quality of Life of elderly. $J$ Welfare for the Aged. 2008 3;39:347-72.

2. Choi YJ, Kim KM, Lee JY, H. KK. Analyzing the time use of rural daily life on farm couple. J Agric Ext Community Dev. 2007;14(1):231-47.

3. Jeon BJ. A study on factors influencing elderly's life time useand occupational balance. Seoul: Sungkyunkwan University; 2010.

4. Nam BH, Jeon SS. Affect the characteristics of the elderly on the quality of life -the resilience and social activity mediated effects. J Soc Welfare Manage. 2016;3(1):279-301. 
5. Yang YS. A study on time use and roles of the older adults in aging society. Korean J Soc Welf Res. 2007;16:1-26.

6. Youngstrom MJ, Brayman SJ, Anthony P, Brinson M, Brownrigg S, Clark GF, et al. Occupational therapy practice framework: domain and process. Am J Occup Ther. 2002;56:609-39. doi:10.5014/ajot.56.6.607

7. Statistics Korea. Survey of household finance and welfare in 20172019 [cited 2019 February 28]. Available from: http://kosis.kr/.

8. Financial Supervisory Service. South Korea's pension system in 2016 Seoul: Financial Supervisory Service; 2019 [cited 2019 Financial Supervisory Service]. Available from: http://www.fss.or.kr.

9. Lee SY, Moon YP. A study of the financial projection of health expenditures of the aged of national health insurance- focused on the healthy ageing of EU. J Criti Soc Welfare. 2018 2(58):53-93.

10. Christiansen $\mathrm{CH}$, Matuska KM. Lifestyle balance: a review of concepts and research. J Occu Sci. 2006 2006/04/01;13(1):49-61. doi:10.1080/14427591.2006.9686570

11. Hanson C, Jones D. Restoring competence in leisure pursuits. 5th, editor. Baltimore, USA: Lippincott, Williams \& Wilkins; 2002. p. 745-57.

12. Meyer A. The philosophy of occupational therapy. Occup Ther Ment Health. 1983;2(3):79-86.

13. Matuska KM, Christiansen C. Life balance: multidisciplinary theories and research. NJ: Slack Incorporated; 2009.

14. Backman CL. Occupational balance: exploring the relationships among daily occupations and their influence on well-being. Can J Occup Ther. 2004;71(4):202-9.

15. Wilcock AA, Chelin M, Hall M, Hamley N, Morrison B, Scrivener L, et al. The relationship between occupational balance and health: a pilot study. Occup Ther Int. 1997;4(1):17-30. doi:doi.org/10.1002/oti.45

16. Hong SP, Lee JY. Time use of areas of occupation according to the periods of life in Koreans. J Korean Soc Occup Therap. 2010;18(1):98-106.

17. Early MB. Mental health concepts and techniques for the occupational therapy assistant. Philadelphia: Williams \& Wilkins; 2000.

18. Robinson JP, Godbey GA. Time for life: the surprising ways Americans use their time. University Park: Pennsylvania State University Press; 1997.

19. Kalenkoski CM, Oumtrakool E. How retirees spend their time: helping clients set realistic income goals. J Finance Plan. 2014;27(10):48-53.

20. Kang JW, Park JH, Park JH. Analysis of time use in healthy elderly: a systematic review. J Korean Soc Occup Therap. 2017;25(2):87-102. doi:10.14519/jksot.2017.25.2.06

21. Jackson J. Living a meaningful existence in old age. Philadelphia: F.A.Davis; 1996. p. 339-61.

22. Amini DA, Kannenberg K, Bodison S, Chang P, Colaianni D, Goodrich B, et al. Occupational therapy practice framework: domain \& process 3rd edition. Am J Occup Ther. 2014;68:S1-S48. 
23. Edgelow M. Efficacy of an occupational time use intervention for people with serious mental illness. Ontario: Queen's University 2008.

24. Hinojosa J, Kramer P. Frames of reference for pediatric occupational therapy. Pediatr Phys Ther. 1993;5(4):213-4.

25. Lee YJ, Joung SH. An analysis of the effect variables of the leisure time consumption of the elderly. $J$ Consum Stud. 2003;14(4):1-19.

26. Kim HM, Shim MK. A comparative study of the time use and quality of life in local community and convalescent hospital of the stroke patient. J Korean Soc Community Based Occup Ther. 2014;4(1):1-10.

27. Hong SY, Kim KM. Time use and occupational balance of mothers with young children. J Korean Soc Occup Therap. 2014 09/30;22(3):125-40.

28. Kim YJ, Hong SP, Park HY. Analysing Korean occupational time changing trend based on ages using 2004, 2009, 2014 time use survey. Journal of Korean Society of Occupational Therapy. 2017 09/30;25(3):13-25. doi:10.14519/jksot.2017.25.3.02

29. Townsend E, Wilcock A. Occupational justice and client centered practice: a dialogue in progress. Can J Occup Ther. 2004;71(2):75-87.

30. Nagle S, Cook JV, Polatajko HJ. I'm doing as much as I can: occupational choices of persons with a severe and persistent mental illness. J Occup Sci. 2002;9(2):72-81.

31. Bejerholm U, Eklund M. Time use and occupational performance among persons with schizophrenia. Occup Ther Ment Health. 2004;20(1):27-47. doi:10.1300/J004v20n01_02

32. McClelland KA. Self-conception and life satisfaction: integrating aged subculture and activity theory. J Gerontol. 1982;37(6):723-32. doi:10.1093/geronj/37.6.723

33. Lee GY. Social activities in later life in Korea. Andragogy Today. 2002 05;5(2):1-22.

34. Cohen. Statistical power analysis for the social sciences. Hillsdale, NJ: Erlbaum; 1988.

35. International Monetary Fund. Capacity development Washington, D.C. : International Monetary Fund (IMF) 2019 [cited 2019 February 28]. Available from: https://www.imf.org.

36. Statistics Korea. Monthly Household Income in 20142019 [cited 2019 February 28]. Available from: http://kosis.kr/.

37. Schulz M, Hartmut R. Die Veränderung der Zeitstrukturen in der Moderne, Frankfurt am Main. Comparativ. 2009;19(1):137-40.

38. Jonathan G. Changing times. Work and leisure in postindustrial society. New York: Oxford: Oxford University Press; 2000.

39. Kim JW. A study on the time of the elderly in Korea: analysing their use of time upon work, family and Leisure. J Welfare Aged. 2006;32:149-77.

40. Joo ES. Work, care or leisure?- the effects of gender and education on time allocation of full-time working parents. Korean J Soc Welf Stud. 2014;45(3):5-34. 
41. Kim TH, Kim DB, Kim MH, Lee YG, Kim AS. A study on improvement of the quality of life for the aged. Korean Geriatr Soc. 1998;18:150-69.

42. Sugisawa $H$, Shibata $H$, Hougham GW, Sugihara $Y$, Liang J. The impact of social ties on depressive symptoms in US and Japanese elderly. J Soc Issues. 2002;58(4):785-804. doi:8080/10.1111/15404560.00290

43. Rogers JC, Holm MB. Performance assessment of self-care skills. Philadelphia: F. A.: Davis; 1994.

44. Christiansen $\mathrm{CH}$, Townsend EA. Introduction to occupation: the art and science of living. $\mathrm{NJ}$ : Pearson Education; 2010.

45. Parham LD, Fazio LS. Play in occupational therapy for children. St. Louis, MO: Mosby; 1997.

46. Bedell GM. Measurement of social participation. New York: Guilford Press; 2012. p. 184-206.

\section{Tables}

Table 1 Older adults' time-use according to the type of occupation (min)

\begin{tabular}{lcrlc}
\hline Occupation & $-1 \mathrm{SD}$ & $\mathrm{M}$ & $(\%)$ & $+1 \mathrm{SD}$ \\
\hline ADL & 126.16 & 185.47 & $(6.90)$ & 244.79 \\
IADL & 1213.99 & 1513.59 & $(56.34 \%)$ & 1813.19 \\
\hline Rest and Sleep & 422.39 & 532.82 & $(19.83)$ & 643.26 \\
\hline Work & -75.32 & 87.83 & $(3.27)$ & 250.98 \\
\hline Education & -16.93 & 3.36 & $(0.13)$ & 23.65 \\
\hline Play & -28.04 & 15.16 & $(0.56)$ & 58.37 \\
\hline Leisure & 126.06 & 292.83 & $(10.90)$ & 459.59 \\
\hline Social Participation & -9.63 & 55.41 & $(2.06)$ & 120.44 \\
\hline
\end{tabular}

$A D L$ Activities of Daily Living, IAD Instrumental Activities of Daily Living

Table 2 Comparison of time-use between occupational balance group and occupational imbalance group. 


\begin{tabular}{|c|c|c|c|c|c|}
\hline \multirow[t]{2}{*}{ Occupations } & $\begin{array}{c}\text { Occupational } \\
\text { Balanced }(n=2153)\end{array}$ & $\begin{array}{c}\text { Occupational } \\
\text { imbalanced }(n=7075)\end{array}$ & \multirow[t]{2}{*}{$\mathrm{t}$} & \multirow[t]{2}{*}{$p$} & $\begin{array}{c}\text { Cohen's } \\
d\end{array}$ \\
\hline & $\mathrm{M} \pm \mathrm{SD}$ & $\mathrm{M} \pm \mathrm{SD}$ & & & $\begin{array}{l}\text { Effect } \\
\text { Size }\end{array}$ \\
\hline$\overline{A D L}$ & $197.84 \pm 50.04$ & $181.71 \pm 61.37$ & $12.39^{* * *}$ & .000 & 0.29 \\
\hline IADL & $1630.77 \pm 179.43$ & $1477.93 \pm 319.11$ & $28.21^{* * *}$ & .000 & 0.59 \\
\hline Rest and Sleep & $571.42 \pm 94.62$ & $521.08 \pm 112.22$ & $20.66^{* * *}$ & .000 & 0.49 \\
\hline Work & $34.02 \pm 80.69$ & $104.20 \pm 177.73$ & $-25.65^{* * *}$ & .000 & 0.51 \\
\hline Education & $3.96 \pm 22.05$ & $3.18 \pm 19.72$ & 1.48 & .140 & 0.04 \\
\hline Play & $10.87 \pm 36.86$ & $16.47 \pm 44.88$ & $-5.85^{* * *}$ & .000 & 0.14 \\
\hline Leisure & $372.18 \pm 145.34$ & $268.68 \pm 165.37$ & $27.99^{* * *}$ & .000 & 0.66 \\
\hline $\begin{array}{l}\text { Social } \\
\text { Participation }\end{array}$ & $4.99 \pm 7.89$ & $70.75 \pm 67.00$ & $-80.73^{* * *}$ & .000 & 1.38 \\
\hline
\end{tabular}

$* * * \mathrm{p}<.001$

Table 3 Factors affecting life satisfaction of occupational balance group 


\begin{tabular}{|c|c|c|c|c|c|}
\hline Predictor & Category & B & $\mathrm{SE}$ & Wald & $\mathrm{p}$ \\
\hline \multicolumn{2}{|l|}{ Age } & 0.02 & 0.00 & $0.02^{* * *}$ & .000 \\
\hline \multirow[t]{2}{*}{ Gender } & Male & -0.12 & 0.05 & $-0.12^{*}$ & .027 \\
\hline & Female & 0.00 & & 0.00 & \\
\hline \multirow[t]{5}{*}{ Educational attainment } & Elementary school & 0.10 & 0.07 & 0.10 & .160 \\
\hline & Middle school & 0.28 & 0.09 & $0.28^{* *}$ & .001 \\
\hline & High school & 0.48 & 0.09 & $0.48^{* * *}$ & .000 \\
\hline & Over college and university & 0.65 & 0.11 & $0.65^{* * *}$ & .000 \\
\hline & No educational attainment & 0.00 & & 0.00 & \\
\hline \multirow[t]{2}{*}{ Marital status } & Married & 0.06 & 0.06 & 0.06 & .265 \\
\hline & Not married & 0.00 & & 0.00 & \\
\hline \multirow[t]{5}{*}{ Reason for needing care } & Dementia & -0.51 & 0.30 & -0.51 & .088 \\
\hline & Stroke & -1.19 & 0.39 & $-1.19^{* *}$ & .002 \\
\hline & Disability & -1.00 & 0.20 & $-1.00^{* * *}$ & .000 \\
\hline & Other reasons & -0.68 & 0.13 & $-0.68^{* * *}$ & .000 \\
\hline & Not need & 0.00 & & 0.00 & \\
\hline \multirow[t]{2}{*}{ Economic activity status } & Working & 0.11 & 0.06 & 0.11 & .057 \\
\hline & Not working & 0.00 & & 0.00 & \\
\hline \multirow{4}{*}{$\begin{array}{l}\text { Average monthly household } \\
\text { income }\end{array}$} & Less than 1 million KRW & -0.43 & 0.07 & $-0.43^{* * *}$ & .000 \\
\hline & $\begin{array}{l}\text { One million KRW } \sim \text { less than } 2 \text { million } \\
\text { KRW }\end{array}$ & -0.32 & 0.07 & $-0.32^{* * *}$ & .000 \\
\hline & 2 million $\mathrm{KRW} \sim$ less than 3 million $\mathrm{KRW}$ & -0.14 & 0.08 & -0.14 & .071 \\
\hline & Over 3 million KRW & 0.00 & & 0.00 & \\
\hline \multirow{2}{*}{$\begin{array}{l}\text { Classifications of agricultural } \\
\text { residence }\end{array}$} & Agricultural residence & 0.29 & 0.07 & $0.29^{* * *}$ & .000 \\
\hline & Non-agricultural residence & 0.00 & & 0.00 & \\
\hline \multirow[t]{5}{*}{ Weekday for research } & Weekdays & -0.03 & 0.05 & -0.03 & .510 \\
\hline & Weekend & 0.00 & & 0.00 & \\
\hline & $\begin{array}{l}\text { Model: -2 Log Likelihoo } \\
.001 .\end{array}$ & $=17300$ & $05, \chi^{0}$ & $=874.31^{* * *}$ & p $<$ \\
\hline & Goodness-of-Fit test: $\chi^{\square}$ & $=2137$ & $.68^{* * *}$, & $\mathrm{p}<.001$ & \\
\hline & $\begin{array}{l}\text { Pseudo R]: Cox and Sne } \\
\text { McFadden=.036. }\end{array}$ & $=.090$, & Nagell & terke $=.098$ & \\
\hline
\end{tabular}

${ }^{* * *} \mathrm{p}<.001 ;{ }^{* *} \mathrm{p}<.01 ;{ }^{*} \mathrm{p}<.05$

\section{Figures}




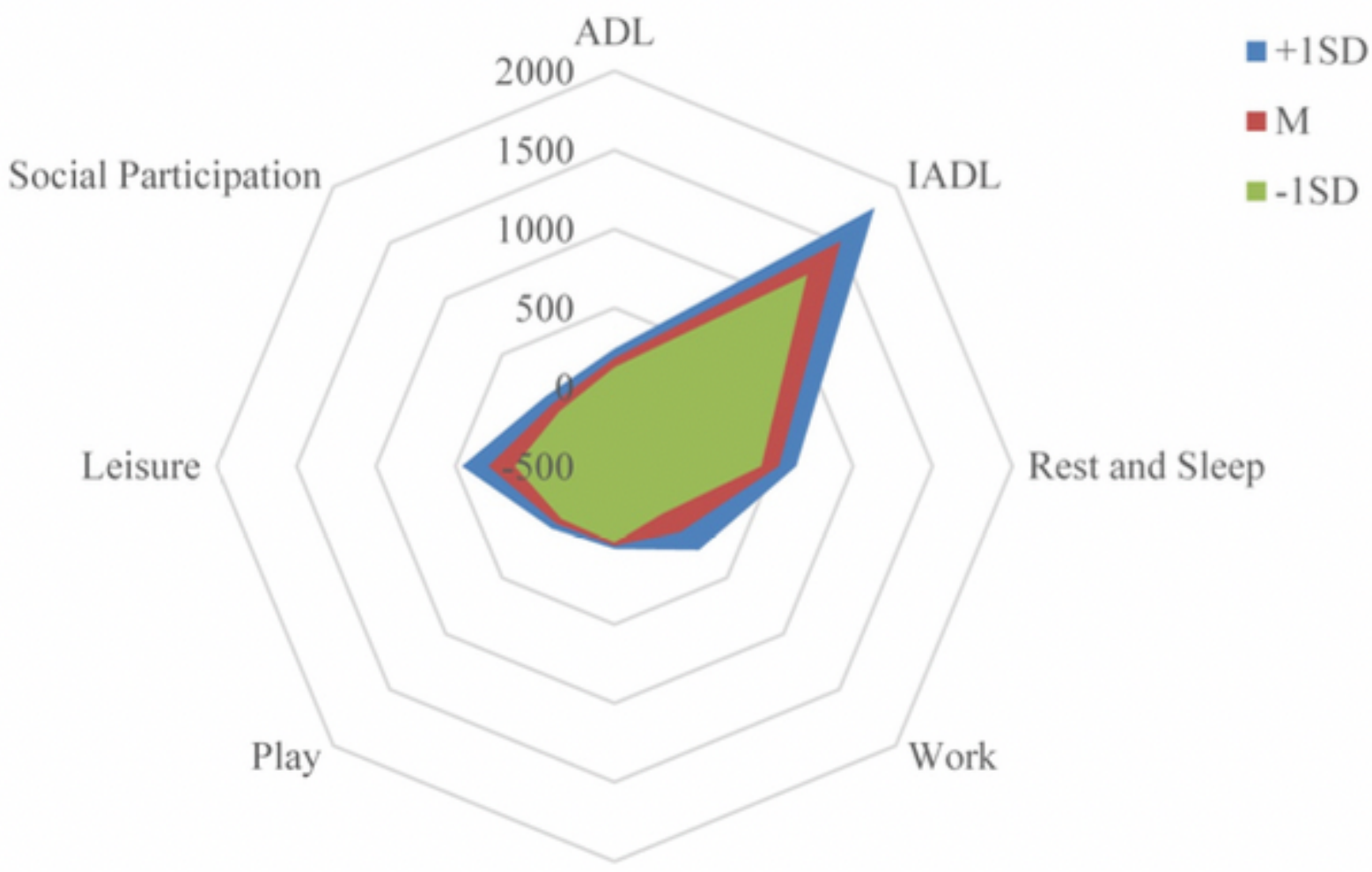

Education

\section{Figure 1}

Mean value and 1 standard deviation (M + - 1SD) of the time-use according to occupations 


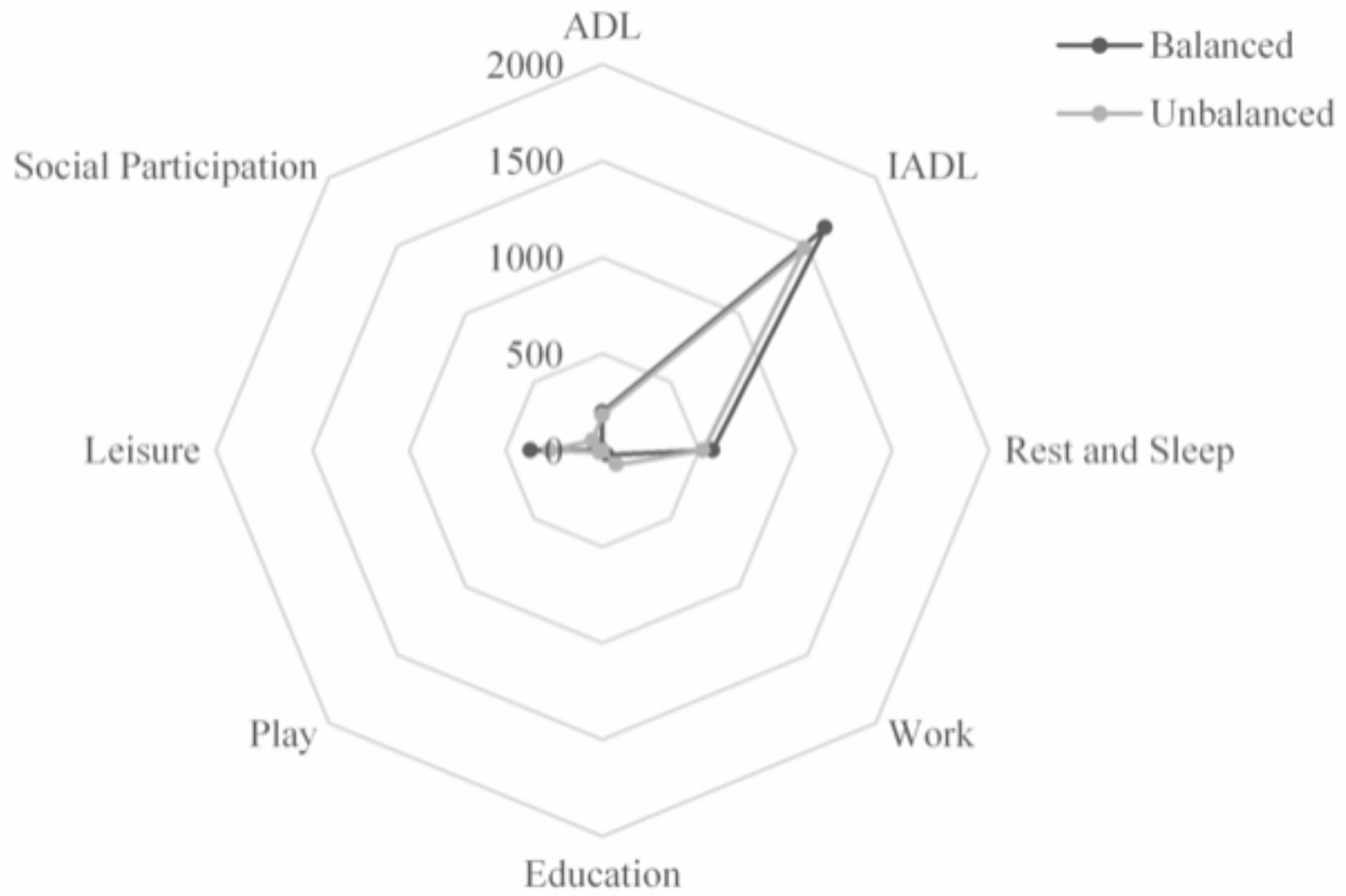

Figure 2

Comparison of time-use between occupational balance (OB) group and occupational imbalance (OI) group

\section{Supplementary Files}

This is a list of supplementary files associated with this preprint. Click to download.

- V1BMCGSupplementaryAppendix12019.8.18.docx 